\title{
EL BANCO DE EMISIÓN DE CHIAPAS, 1902-1908. UNA EXPERIENCIA SINGULAR A FINALES DEL PORFIRIATO
}

J. Manuel Salinas Sánchez jmsalinass_@hotmail.com

\section{RESUMEN}

Los estudios económicos y financieros del estado chiapaneco son prácticamente nulos. Aun siendo uno de los factores fundamentales para entender las causas que originaron su rezago y marginación, no se ha puesto énfasis en concebir y exponer que este proceso marcó el destino de la entidad. La finalidad de este artículo es buscar una explicación acerca de los factores que no permitieron que la región, que se había convertido en una proveedora de materias primas y productos agropecuarios para el mercado internacional, pudiera erradicar los rezagos de una sociedad preindustrial que siguió manteniendo vestigios coloniales que fueron suprimidos hasta ya bastante entrado el siglo XX.

Palabras Clave: banco, moneda, numerario, agio y grupos de poder.

\begin{abstract}
Overview economic studies and financial of the Chiapas State are practically nil. Even as one of the key factors to understand the causes that originated the backwardness and marginalization, has not been an emphasis on design and expose this process marked the destiny of the entity. The purpose of this article is to seek an explanation of the factors that did not allow the region, which had become a supplier of raw materials and agricultural products to the international market, could eradicate the shortcomings of a pre-industrial society that continued to maintain colonial vestiges that were suppressed until now quite entered the 20th century.
\end{abstract}

Key words: Bank, currency, cash, agio and power groups. 


\section{INTRODUCCIÓN}

La imperiosa necesidad de integrar a Chiapas al mercado nacional e internacional obligaba a las autoridades estatales a realizar obras de infraestructura en las vías de comunicación, pero los pocos recursos con los que contaba la Hacienda Pública Estatal no le permitían realizar esta labor. A diferencia de estados como Chihuahua, Durango, Sonora, Zacatecas, que se habían beneficiado con la creación de vías férreas que les permitían sacar al exterior sus productos, Chiapas seguía sufriendo por carecer de ellas hasta los primeros años del siglo XX. Aquellos estados, para realizar este tipo de obras se habían apoyado en instituciones de crédito que fueron creciendo con los proyectos de inversión que desarrollaban, acorde con la idea de la administración federal de impulsar el despegue del sistema bancario del país. Se pensó que con la creación de bancos locales se podría lograr el objetivo de impulsar el desarrollo industrial. Bajo este esquema se fundó el Banco de Emisión de Chiapas en 1902, al cual denominaremos de aquí en adelante como BCh, que tenía la finalidad de impulsar la creación de una vía férrea en el estado, obra necesaria para integrarse al proceso de modernidad que exigía la administración federal.

El BCh pretendió marcar el destino financiero de la entidad, pero no contó con que se iba a enfrentar a situaciones que estaban fuera de su alcance y no eran fácilmente negociables: El agio estaba bastante arraigado. El numerario nacional no cubría las necesidades del mercado local y circulaba en su lugar la moneda centro y sudamericana a la que se le denominaba «Cachuca». Por desconocer las funciones de los bancos, la población no confiaba en ellos, se rehusaba a utilizar el papel moneda. La captación de recursos que obtuvo de 1902 a 1908 fue muy baja. Las crisis económica de 1905 y de exportaciones de 1907 le afectaron enormemente, lo que orilló a los inversionistas a promover su fusión con el Banco Oriental de México con sede en Puebla, al cual denominaremos de aquí en adelante como BOM, de capital español mayoritariamente, cuyo su principal accionista era Manuel Rivero Collada, banquero y empresario que tenía la visión de formar una institución financiera regional que abarcase los estados de Puebla, Tlaxcala, Oaxaca y Chiapas, ${ }^{1}$ en oposición al Banco Nacional de México $^{2}$ (Banamex) y el de Londres y México, quienes gozaban de ciertos privilegios en la administración porfirista. Estas 
situaciones marcaron el destino del BCh ocasionando su fusión y convirtiéndose así en una sucursal del BOM.

La creación de un banco local se había convertido en una necesidad exigida por el proceso de inserción del estado en el mercado mundial. Chiapas, desde las últimas dos décadas del siglo XIX, figuraba como productora y exportadora de materias primas y artículos agropecuarios, que requerían las naciones industrializadas y se producían en la región. El estado era inminentemente rural y los inversionistas extranjeros que se habían estacionado en estas regiones canalizaron sus esfuerzos en la producción de estas mercancías, como fue el caso del Soconusco con el café, cacao y ganado vacuno; Pichucalco, con el maíz, café y caucho; la zona de los Altos con el trigo, además de maderas finas, añil y licores, entre otros. ${ }^{3}$ Pero las circunstancias no permitieron que se cimentara y afianzara esta institución crediticia.

\section{GÉNESIS DEL BANCO DE CHIAPAS}

Con la expedición de la Ley General de Instituciones de Crédito de 1897, la administración porfirista reglamentaba el funcionamiento de la banca en el país. Con esta ley se pretendía salvar el caos y anarquía con que trabajan los bancos en esta época. Ahora tendrían la tarea de fomentar proyectos de inversión en los estados para insertarse en el proyecto de desarrollo que tanto anhelaba la política porfirista. La visión era elevar a la nación a la altura de los países industrializados y para ello se requería abrir las fronteras a los capitales extranjeros, que podrían, según la política del momento, insertar a la nación en el tren de la modernidad, sueño acariciado por el presidente Díaz. Con esta idea y al amparo de esta ley se funda el Banco de Chiapas, que abrió sus puertas en febrero de 1902. ${ }^{4}$

Dicha ley había previsto la creación de bancos en las modalidades de: ${ }^{5}$ Refaccionarios, que brindaban créditos agrícolas e industriales a mediano plazo; Hipotecarios, con créditos territoriales a largo plazo (una especie de continuación de los préstamos eclesiásticos); y los de Emisión, que hacían circular billetes de diversas denominaciones, daban préstamos cortos de hasta seis meses y recibían depósitos, convirtiéndolos en una fuente de fondos 
muy socorrida. Esta última modalidad se permitió perentoriamente porque la administración federal no contaba con un Banco Central que regulara la emisión de moneda fiduciaria, pero además porque la moneda acuñada no alcanzaba a cubrir las necesidades financieras del país. La expedición de papel moneda cubría esta necesidad y además les servía a los bancos de emisión porque la consideraban una fuente de fondos. El papel moneda jugó un rol importantísimo en el desarrollo de las instituciones bancarias. «La emisión de billetes permitía a los bancos financiar a su clientela, era un aliciente muy fuerte para los banqueros, que para prestar, no tenían que depender exclusivamente de su capital, ni esperar depósitos de clientes no habituados a hacerlos». ${ }^{6}$ Los billetes eran pagaderos al portador y a la vista en moneda metálica (plata u oro), ${ }^{7}$ cuya oferta controlaban internamente pues se sujetaban a lo que disponía la Comisión de Cambios y Moneda.

El BCh se ubicó en el renglón de Emisión porque esta modalidad le permitía expedir sus propios billetes, y con esta opción la administración concibió la idea de cubrir los gastos que generaría la construcción del Ferrocarril Panamericano, obra primordial de fundadores e inversionistas de esta institución. Además, tendría el monopolio regional de la moneda al no existir otra institución crediticia en el estado, podrían captar los recursos cautivos de la localidad; pero no obtuvieron los resultados esperados, este error de cálculo obligó a los inversionistas iníciales a desistir de su cometido en cinco meses; los depósitos de la clientela no fueron suficientes para amortizar los gastos de la obra en cuestión, y es que la falta de ahorradores fue una constante que se prolongó indefinidamente a pesar que «a partir de 1903 se había puesto de moda pagar intereses sobre los depósitos, práctica que entre la clientela fue acogida con el beneplácito que era de esperarse» ${ }^{8}$

Por ser los bancos instituciones nuevas y por desconocer su funcionamiento, los clientes potenciales desconfiaban del uso de papel moneda para realizar operaciones mercantiles, estaban habituados a utilizar la moneda acuñada en sus transacciones por ser esta símbolo de valor y expresión auténtica del dinero, se resistían a considerar los billetes como medida de valía. Pero además la población no estaba acostumbrada a utilizar el sistema bancario para depositar sus ahorros. Solo en situaciones emergentes, un sector de la población se vio 
obligado a utilizar estos bancos para depositar sus capitales, y esto fue porque en la capital chiapaneca, en 1906, se habían suscitado una serie de «robos a casas habitación y habían hurtado el dinero que en ellas atesoraban sus habitantes, hecho que obligó a otros ciudadanos a recurrir a cualquiera de los dos bancos que existían en la localidad para asegurar su patrimonio». ${ }^{9}$

La tarea que habían emprendido los fundadores del banco era muy compleja, la repartición de la riqueza en el estado era extremadamente desigual; de los 360,799 habitantes que había arrojado el censo de $1900,{ }^{10}$ aproximadamente el 80\% era de origen indígena, el 15\% albergaba a los mozos y baldíos, y en el 5\% restante se consideraba a los hacendados, grandes finqueros y comerciantes, ${ }^{11}$ personajes que podían incluirse en uno o más segmentos. Eran estos quienes controlaban las ligas comerciales, crediticias y financieras del estado, y como realizaban operaciones de crédito y fomentaban el agio no necesitaban el servicio bancario. Por esta razón los depósitos a estas instituciones se reducían drásticamente. Aunado a lo anterior, tenían el problema de la moneda Cachucaque, que había invadido la entidad desde finales de la Colonia y era bien acogida por la población en la localidad, siendo aceptada como moneda de curso legal u oficial en el estado. ${ }^{12}$ Esta situación afectó enormemente a los inversionistas que no previeron que podrían encontrar una gran resistencia por parte de la población para aceptar los billetes emitidos por ellos, ${ }^{13}$ teniendo que competir con la moneda «cachuca».

Desde el punto de vista económico, el establecimiento de una institución de crédito era necesario. La urgencia por integrar el mercado local con el centro y norte de la República se había vuelto una imperiosa necesidad. La fragmentación y lejanía en que se encontraban los centros mercantiles locales con respecto al centro de México ocasionaban que, Comitán por ejemplo, a través de su frontera con Guatemala, realizara sus operaciones comerciales y mercantiles con moneda guatemalteca, aun a pesar de los riesgos que esto representaba para los comerciantes mexicanos, dada la gran fragilidad de la estructura económica de la nación guatemalteca para esas fechas. Sin embargo, no había mucha opción, puesto que la moneda nacional no llegaba fácilmente a estas regiones debido al aislamiento en que se 
encontraba con respecto al mercado nacional, así como la carencia de vías de comunicación para trasladar sus productos a los mercados nacionales.

El BCh se fundó por la labor de convencimiento que habían realizado José Mora, gestor de inversiones y amigo del presidente Díaz, y James M. Neeland, un comerciante californiano, con inversionistas norteamericanos de Lyons, Nebraska y Los Ángeles California, ${ }^{14}$ quienes habían adquirido experiencia en la administración de bancos en su ciudad natal. Tal es el caso de Franklin Everett, quien había administrado el primer banco en Lyons en 1881 con buenos resultados. Sin embargo, era notorio que a este grupo de capitalistas les interesaba y, de manera prioritaria, la construcción de la línea férrea. A estos se les unió Enrique C. Creel, quien, junto con Mora, pertenecía al grupo de los «científicos». ${ }^{15}$ Creel se había destacado como un precursor de negocios en su estado y se embarcó en la labor de ser accionista de esta nueva institución bancaria; además, contaba con alguna experiencia ya que había sido fundador y gerente del Banco Minero de Chihuahua; es decir, al menos en apariencia la administración de esta institución parecía tener asegurado su buen funcionamiento. El Consejo de Administración quedaba integrado de la siguiente manera:

Cuadro 1. Integración del Consejo de Administración del BCh.

\begin{tabular}{|l|l|l|l|}
\hline \multicolumn{1}{|c|}{ Nombre } & \multicolumn{1}{c|}{ Origen } & \multicolumn{1}{c|}{ Posición } & \multicolumn{1}{c|}{ Residencia } \\
\hline Franklin Everett & Lyons, Nebraska & $\begin{array}{l}\text { Accionista } \\
\text { mayoritario }\end{array}$ & Nebraska \\
\hline Waldo Lyon & Lyons, Nebraska & $\begin{array}{l}\text { Accionista } \\
\text { mayoritario }\end{array}$ & Nebraska \\
\hline Charles F. Earle & Los Ángeles, Ca. & Accionista & Nebraska \\
\hline Enrique C. Creel & Chihuahua & Accionista y asesor & Chihuahua \\
\hline Ciro Farrera & Tuxtla, Chiapas & Accionista & Tuxtla Gutiérrez \\
\hline Walter Everett & Lyons, Nebraska & Presidente & Cd. de México/Tuxtla \\
\hline Fremont Everett & Lyons, Nebraska & Gerente General & Tuxtla Gutiérrez \\
\hline Edwad B. Everett & Lyons, Nebraska & Tesorero & Tuxtla Gutiérrez \\
\hline Alfred B. Lyon & Lyons, Nebraska & Pagador & Tuxtla Gutiérrez \\
\hline Delbert B. & Lyon Lyons, Nebraska & Cajero & Tuxtla Gutiérrez \\
\hline José Mora & Oaxaca & Promotor & Tuxtla/Cd. de México \\
\hline James M. Neeland & Los Ángeles, Ca. & Promotor & Tuxtla/Cd. de México \\
\hline J.C. Newton South & Pasadena, Ca. & Accionista menor & Tuxtla Gutiérrez \\
\hline Mariana de Coronel & South Pasadena, Ca. & Accionista menor & Tuxtla Gutiérrez \\
\hline
\end{tabular}


La falta de un estudio profundo sobre las condiciones del estado en 1902 ocasionó que la administración fundadora del BCh claudicara y cediera sus derechos a empresarios locales. Estos, conocedores de la problemática interna, sabían que en las últimas dos décadas del siglo XIX ingresaron a la región grupos de inversionistas extranjeros que habían logrado arraigarse porque sus capitales, además de hacer productivas sus fincas rústicas y haciendas, también los utilizaron para realizar operaciones de crédito. Fungieron como agentes financieros, labor que se les facilitó por contar con el apoyo de las casas comerciales y crediticias de Europa y los Estados Unidos.

Aunque el BCh fue una esperanza para algunos sectores de la población, la institución desde sus inicios se enfrentó a ciertos problemas de liquidez y Rafael Pimentel, gobernador del estado, reconoció en su informe de 1902 que, «si bien tuvo al principio las dificultades de todo negocio nuevo, ha regularizado ya sus operaciones que es indudable irán ensanchándose más cada día». ${ }^{17}$ Para esta fecha se había realizado el cambio de administración solicitado por los inversionistas iniciales, con Walter Everett como presidente y vocero. Habían decidido dejar la institución por la poca rentabilidad que habían observado en cinco meses de actividades. ${ }^{18}$ El primer y único balance conocido del 31 de marzo de 1902 reflejó cero billetes en circulación, lo que hablaba de la nula aceptación de la gente al papel moneda, y aunque había sesenta mil pesos en depósitos por ahorros, era dinero reembolsable. Por el contrario, registraron 15,822 pesos en gastos de organización y nómina, e hicieron préstamos por 26,675,40; en suma, había más erogaciones. ${ }^{19}$

Ramón Rabasa, hermano del ex gobernador Emilio Rabasa, aprovechando los nexos que había adquirido al desempeñarse como jefe político de Tuxtla y tesorero general de gobierno, y apoyándose en las ligas que había cultivado su hermano en la ciudad de México, tomó la decisión de rescatar esa institución financiera. ${ }^{20}$ Para hacerlo reunió a un grupo de capitalistas locales y extranjeros con la idea de hacerlo rentable. Como principal promotor siguió James M. Neeland, quien vigilaba en las relaciones con los bancos centrales mexicanos y el United Status Banking Company, además incorporó a Max Newmark y Berthold Baruch, dos empresarios judíos residentes en Los Ángeles, 
California, que llegaron a México en un viaje de excursión en diciembre de 1901 y residieron en Tuxtla por un tiempo. ${ }^{21}$ Este tipo de instituciones le eran desconocidas a la población y para que pudieran tener confianza en una entidad de esta naturaleza era necesario conocer a quien la dirigía, por lo tanto se pensó que con la incorporación en el consejo de administración de hombres de reputación honorable y solvencia económica de la localidad podrían salvar esta situación con los clientes que se habían acercado para depositar sus ahorros, y con este referente podrían convencer a los demás usuarios potenciales para depositar su dinero en este banco. El nuevo consejo administrativo quedó integrado de la siguiente manera:

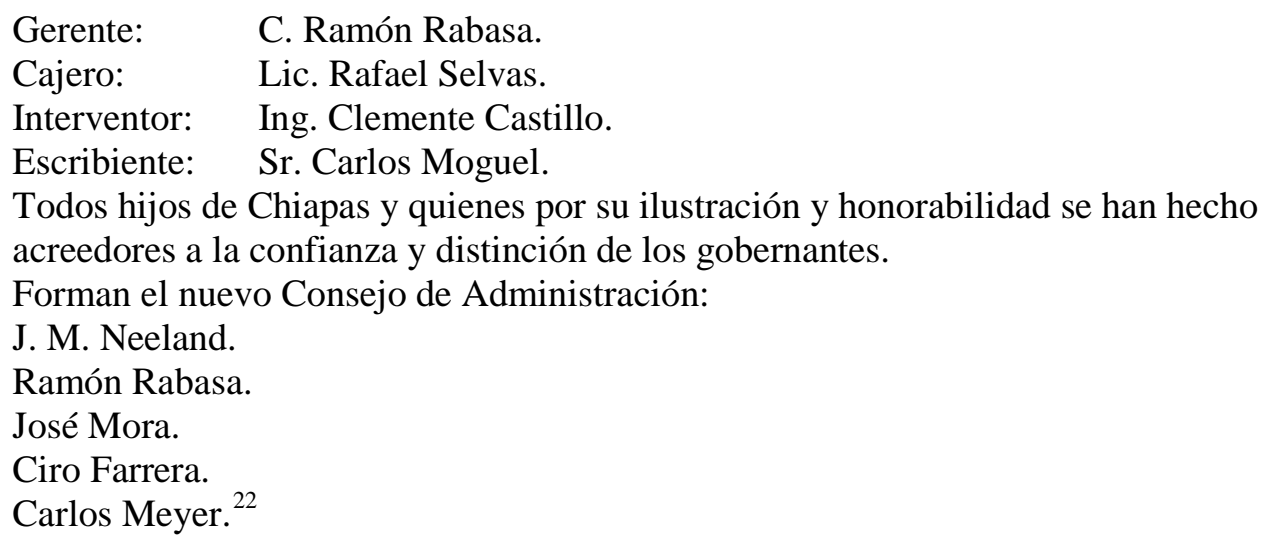

El capital social que reportó el banco en su creación fue de \$500,000.00, pero solo presentó $\$ 255,000.00$ en metálico, y emitió billetes por \$500,000.00; afortunadamente no se excedieron en su emisión, como puede apreciarse en los balances mensuales. El flujo de estos billetes más los depósitos a la vista y los saldos de las cuentas corrientes hacían difícil la situación de la institución. La diferencia entre el capital social y el capital no exhibido no se regularizó hasta octubre de $1905,{ }^{23}$ cuando reunió la cantidad de $\$ 245,000.00$ pesos para cubrir la totalidad de su capital social.

Para hacerse cargo de la gerencia del BCh, Ramón Rabasa renunció al puesto que desempeñaba en la administración pública, donde había conocido a comerciantes y particulares que estaban autorizados para recibir billetes, hacer giros y préstamos en las principales plazas de la entidad. Con esta oportunidad la elite tuxtleca fue tejiendo los hilos para ir tomando el control político y regir el destino del estado de una forma más firme. De 
los grupos de poder, el de Tuxtla era más fuerte y consistente que el de San Cristóbal. Aun dentro de estos grupos siempre iba a existir uno que se quedara rezagado respecto a los demás, y este era el caso de la zona de Los Altos. Así Ramón Rabasa comenzó a cerrar filas con las elites de Comitán, Tonalá, Soconusco y Tuxtla, en contraposición a San Cristóbal, Chilón, Pichucalco y en cierta forma Palenque, que presionaban al gobernador en turno para ser beneficiarios de los negocios que se operaban en la administración pública y que hasta este momento habían favorecido solo al grupo que representaba la elite tuxtleca. De esta manera, Ramón Rabasa organizó al grupo que monopolizaría el flujo de capitales estatales y nacionales con el apoyo de los agentes bancarios diseminados en el estado; algunos de estos se convirtieron posteriormente en accionistas del banco. A través del Periódico Oficial, se dio a conocer a las personas y comercios que fungirían como representantes del BCh, de la siguiente manera:

Participamos al público que son agentes de este Banco:

Don Mariano S. Trujillo, en San Cristóbal Las Casas

Don Manuel E. Guzmán, en Cintalapa

Don Enrique Rau, en Palenque y Chilón

Señores Schauenburg y Meyer en Comitán

Señores R. Corzo y Cía. en Chiapa y

M. Forteza y Cía. en Pichucalco

Dichas agencias cambiaran nuestros billetes a la par y están autorizadas para hacer giros y atender toda clase de negocios que se relacionen con esta Institución. ${ }^{24}$

Ya concluidas las labores de organización, la siguiente tarea era captar recursos y qué mejor cliente que el gobierno local, terreno que le era familiar a Ramón Rabasa. Gracias a su paso por la administración pública conoció los renglones donde se invertía lo recaudado e identificó las necesidades y carencias de la Tesorería. Con estos antecedentes le propusieron al gobernador Rafael Pimentel suscribir un convenio entre el banco y su administración para que esta institución hiciera la función de concentradora de fondos en la recaudación de impuestos a través de sus agentes, propuesta que aceptó Pimentel tratando de esta manera que la negociación que aceptaba se estipulara en los siguientes términos:

Cábeme, pues, la satisfacción de informar que no obstante las dificultades enumeradas hasta aquí, no se ha recurrido a ningún medio oneroso para contrarrestar el periodo de crisis, pues si bien es cierto que usando de facultades anteriormente concedidas, se ha abierto una cuenta de intereses recíprocos entre el 
Banco de Chiapas y la Tesorería General, esta operación no ha revestido el carácter de empréstito, sino que ha tenido por base preferente facilitar la concentración de fondos del Erario existentes en Departamentos de difícil contacto mercantil con la capital. $^{25}$

De esta forma, el gobernador firma el convenio y el BCh se convierte en recaudador de los fondos de la Tesorería; así, el banco le otorgaba al gobierno los recursos que requería sin que se considerada un crédito, las cantidades que le eran entregadas a la Administración Pública nunca se reflejaron en los balances del BCh en el renglón de créditos otorgados, sino en el de cuentas corrientes. En este sentido, el gobierno no tendría que estar renovando cada seis meses y tampoco debía justificar el destino de estos créditos, ya que en la realidad no eran tales. Los saldos de la cuenta gubernamental podrían variar entre ser deudores o acreedores, y en ese caso el banco pagaba o cobraba intereses por los saldos que reportaba mensualmente. La posición del gobernador Pimentel era de no adquirir compromisos con entidades financieras, tratando de no comprometer las arcas de la hacienda local, ${ }^{26}$ posición contradictoria pues tenía adeudos con particulares, como era el caso de Pedro del Cueto.

La captación de recursos fue una limitante para el banco, las cifras del balance mensual lo reflejan. El renglón de depósitos a la vista o a plazo mostraba cantidades poco significativas como para aventurarse a expedir créditos por cantidades considerables, pues no existía la práctica del ahorro. Esto aunado a que el grueso de la población era indígena y no percibía un ingreso seguro, los mozos y baldíos acasillados en fincas rústicas y haciendas tampoco podían ahorrar, la carencia de una clase media que fuera la proveedora de recursos a la institución y por último los dueños de las fincas, haciendas y grandes comerciantes le daban otra utilidad a sus capitales, los ocupaban en la práctica del agio.

El año de 1906 fue crucial para definir el destino del BCh. Ramón Rabasa dejó la administración del banco para convertirse en gobernador interino porque Rafael Pimentel había enfermado y esto le impedía continuar en el cargo. En esto, no es difícil suponer que la influencia que Emilio Rabasa tenía con Porfirio Díaz le hubiera sugerido suplir la vacante con su hermano Ramón, ya que veía en Pimentel un peligro que podría poner en 
riesgo su influencia en la región por las simpatías que había cultivado este con la elite sancristobalense. Podría pensarse que la reforma monetaria de 1905 había puesto nerviosos a los inversionistas del banco, pero no fue así, el BCh afirmaba que la reforma monetaria no había impactado en sus operaciones e informaba que en 1905 su actividad había sido «satisfactoria», y como prueba presentaba las utilidades del año comparándolas con las anteriores: 1903, \$14,253.00; 1904, \$16,932.02, y 1905, \$35,232.50. Aparentemente esa podría haber sido la razón de que Ramón tomara las riendas del Estado, pero fue más que eso: su decisión fue más política que financiera, pretendía encumbrarse en el poder y esta era su oportunidad porque era la única persona en la que confiaba su hermano Emilio para seguir influyendo en la política local. Es cierto que en ese mismo año Banamex había conseguido la autorización para abrir sucursales en Tuxtla y otra en Tapachula, y que aparentemente esto ponía en riesgo la inversión que había realizado con el BCh, pero Ramón estaba consciente que las prerrogativas que dicha institución había obtenido de la administración porfirista le daba la facultad de abrir sucursales en donde juzgara pertinente, y ahora se había fijado en el estado de Chiapas. Para Ramón, el hecho de ser el hombre fuerte del estado le aseguraba a su grupo mantener las riendas de la política que debía aplicarse en la entidad de acuerdo con su conveniencia.

Cuando Ramón tomó la gubernatura, dejó la administración del banco en manos de Rómulo Farrera, un comerciante y finquero local incondicional de su grupo, afianzando así el liderazgo de la familia Rabasa. Para Ramón, el banco ya no era prioridad y decidió dejarlo que siguiera su propia dinámica. Para estas fechas ya se habían contactado con el presidente del BOM, Manuel Rivero Collada, ${ }^{27}$ para negociar la fusión. Una vez de acuerdo se pedía a los accionistas del BCh que depositaran sus acciones en sus oficinas o en las de los bancos Nacional de México, Central Mexicano, del Descuento Español u Oriental de México, para exponerlo en la Asamblea General del 25 de marzo de $1907 .{ }^{28}$ En esta asamblea se acordó gestionar la fusión con el Banco Oriental. ${ }^{29}$

La crisis de 1905 fue provocada porque José Ives Limantour, secretario de Hacienda, se había propuesto integrar el sistema monetario de México, basado en la plata, al sistema monetario de Estados Unidos y Gran Bretaña basado en el oro. La idea de este proyecto era 
integrar la economía de México a esos países mediante el peso de oro y fuera compatible con el dólar de oro para equilibrar la balanza comercial y de pagos. Para esto, las reservas de oro de México estarían depositadas en Nueva Cork, con el fin de facilitar los pagos de negocios entre México y el resto del mundo a través de esta entidad. Con esta reforma se logró que nuestro sistema monetario, que por siglos había estado basado en la moneda de plata, cambiase a un sistema basado en oro. Al efectuarse el cambio, surgieron graves problemas en México, a tal grado, que se afectó severamente la mano de obra agrícola, industrial y hasta a la naciente clase media, hecho que impactó al estado chiapaneco, que basaba su economía en capitales extranjeros. El nerviosismo originado por el cambio de patrón monetario, aunado a la disminución de exportaciones a los mercados norteamericanos, reafirmó la decisión de los inversionistas del BCh de efectuar la fusión, y es que:

[...] El gran flujo de inversiones extranjeras después de 1900 había hecho al país más dependiente de las naciones industriales avanzadas; la adopción del patrón oro por México en 1905 había frenado el crecimiento económico, y la crisis cíclica que ocurrió en los Estados Unidos durante 1907-1908 tuvo un efecto devastador sobre México en general. ${ }^{30}$

Este fue el último trago amargo de los inversionistas del BCh para fusionarse con el BOM, el cual tenía mayor capacidad para competir en el estado con la sucursal que Banamex había abierto desde principios de 1906, donde José M. Casteló firmó como apoderado de este banco con el Ejecutivo del estado, dándole la opción de abrir las sucursales que fueran necesarias. ${ }^{31}$ Por la ubicación geográfica del estado era necesario que tuviera presencia una institución de esta naturaleza, pues el flujo de capitales se daba en moneda extranjera, la «cachuca», dólares norteamericanos, marcos alemanes, entre otros; porque el numerario nacional por ser insuficiente no llegaba a la región y las ganancias obtenidas los capitalistas las llevaban fuera del país. Banamex también enfrentó el problema de falta de ahorradores y lo obligó a posponer la apertura de otra sucursal en Tapachula, donde solo instaló una agencia que abrieron el 3 de enero de 1908, la cual dio a conocer Pedro del Cueto al gobernador del estado. ${ }^{32}$ Del Cueto había fungido en el estado como agente de Banamex y estaba consciente del flujo de operaciones que realizaban los capitalistas 
extranjeros, ${ }^{33}$ por eso no era nada casual que los capitalistas poblanos se interesaran en integrar al BCh a su consorcio financiero.

Como era de suponerse y con la idea de tomar el control en el aspecto financiero y crediticio, Banamex, a través de la sucursal de Tuxtla, le propuso a la administración local abrirle una línea de crédito que fue autorizada bajo las siguientes condiciones:

[...] el Decreto número 10 de 18 de mayo anterior, autorizó al ejecutivo a abrir cuenta corriente con el Banco Nacional de México, o con la sucursal que tienen establecida en esta ciudad, hasta por la cantidad de $\$ 50,000.00$, con intereses recíprocos de 8\% anual. El Gobierno procedió de conformidad a fin de facilitar el movimiento de caudales del Estado y de poder disponer en su oportunidad de los fondos indispensables para satisfacer las necesidades de la Administración evitando las dificultades que muchas veces se presentan en el intervalo de cada tercio en que se hace la recaudación. ${ }^{34}$

Esta se dio al amparo de la concesión que la administración federal le había otorgado a Banamex, donde estipulaba que en terrirorio nacional sus sucursales serían las recaudadoras de los impuestos federales. Esta sola disposición hizo que los ingresos que recaudaba el BCh fueran más restringidos y prolongara su agonía hasta 1909. Las acciones que emprendió Ramón Rabasa para fortalecer al Banco de Chiapas fueron infructuosas y sucumbieron ante las presiones y propuestas del Banco Oriental. Ganar con dinero prestado (o ajeno) era uno de los encantos que el negocio bancario ofrecía -y ofrece- a sus inversionistas, pero las condiciones en que operó el BCh no lo permitieron. No así a los directores del Oriental, que sin invertir incrementaron su capital social con los pasivos que contaba el de Chiapas.

La lucha entre el BCh y los empresarios financieros locales fue muy difícil de superar, situación que persistió hasta 1906, cuando el BCh abrió una sucursal en Tapachula y tenía planeada otra en Tonalá, como lo estipulaba la escritura que registró el notario público Enoch Paniagua. ${ }^{35}$ En febrero de 1906 se abrió la sucursal del BCh en Tapacula, ${ }^{36}$ de la cual era gerente R. O. Stevenson, ${ }^{37}$ un hacendado de la localidad, a quien ratificó la Secretaria de Hacienda para ocupar dicho cargo $^{38}$ En dicha escritura se estipulaba la 
apertura de una sucursal en la ciudad de Tonalá, que no llegó a concretarse por la crisis que estaban pasando tanto el banco como los productores locales ocasionada por la recesión de la economía norteamericana. ${ }^{39}$ Es posible aventurar que la apertura de la sucursal de Tapachula por el BCh se dio por la expansión que estaba realizando Banamex hacia el sureste, institución a la cual veían como un peligro latente.

Esta gama de empresarios-financieros florecieron con la complacencia de la administración porfirista. Estos inversionistas mantenían las características de los comerciantes que dominaron el escenario económico de la nación en la primera mitad del siglo XIX, eran aquellos que, de una manera diferente a los industriales y mercaderes, comprometían su capital en operaciones de crédito destinadas a proporcionar recursos a las actividades mercantiles y productivas de los estados, obteniendo jugosas utilidades pues sus principales clientes eran regularmente las administraciones públicas. Esto les permitió gozar de ciertos privilegios, como el monopolizar los negocios públicos, obtención de tierras y permiso para realizar funciones de banca que les fueron bastante redituables. Chiapas no fue la excepción, los agiotistas locales, contagiados por la fiebre de obtener ganancias seguras, se dieron a la tarea de convertirse en este tipo de agentes aprovechando las ligas financieras y comerciales que mantenían con las principales agencias y bancos del viejo conteniente y de los Estados Unidos de Norteamérica. Su próspero desarrollo permitió que algunos de estos capitalistas obtuvieran el reconocimiento de sus países de origen para ser nombrados cónsules nobiliarios en la localidad por la patria de la cual eran originarios, como Pedro del Cueto en Tuxtla Gutiérrez y José Revuelto en Tapachula, quienes se convirtieron en vice-cónsules de España, ${ }^{40}$ y R. O. Stevenson por Inglaterra.

En Chiapas, estos empresarios-financieros estaban establecidos en Tuxtla y Soconusco principalmente, y en menor medida en Comitán, Pichucalco, Chilón y Palenque. Eran dueños de haciendas y fincas rústicas y se iban perfilando como el sector más progresista de la entidad. Este grupo tuvo la oportunidad de allegarse a la administración pública en 1891, cuando tomó las riendas del estado Emilio Rabasa, quien tenía una formación liberal. Su lema de gobierno, «Renovación y Progreso», así lo indicaba y el sector emprendedor encontró en este joven un aliado para impulsar sus proyectos de inversión, liberando la 
tierra y los impuestos onerosos de que eran causantes. Así, la elite tuxtleca se unió para formar el grupo hegemónico que orquestaría la política de la administración pública e influiría en las disposiciones oficiales logrando mantener este control hasta 1914.

Emilio Rabasa había asumido la gubernatura en 1891, periodo en que la política de Porfirio Díaz estaba en su mejor momento. Con su respaldo, Rabasa realizó ciertos cambios para impulsar el proyecto que sacaría a Chiapas de la miseria; esto provocó el descontento de la elite sancristobalense que se sintió marginada con el cambio de ciudad de la capital del estado. Cuando Rabasa tomó el gobierno, este se encontraba con problemas financieros muy serios. La hacienda pública no podía sostener su administración. Para remediarlo, solicitó apoyo a los capitalistas de Las Casas, pero no encontró la ayuda esperada. Esta negativa, aparentemente, fue la que orilló al gobernante a trasladar los poderes a la ciudad de Tuxtla Gutiérrez; pero hubo otras razones que tocaré en otra ocasión. Los comerciantes tuxtlecos le facilitaron dichos recursos sin poner objeción alguna; entre ellos estaba Pedro del Cueto, un comerciante-financiero que proporcionó lo solicitado. ${ }^{41}$ Las necesidades económicas del estado eran evidentes y era muy común en estas fechas que los gobiernos recurrieran a estos agentes financieros. En Chiapas, a pesar de que en 1901 el Ejecutivo Federal le había concedido a la administración local la autorización para abrir una cuenta corriente hasta por $\$ 30,000.00$ pesos y con el «premio» del $9 \%$ anual con uno de los bancos de la capital de la República, este no fue utilizado, ${ }^{42}$ quedándose con la deuda de Pedro Del Cueto, quien se había destacado como un prominente empresario que contaba entre sus bienes con una fabrica de cigarrillos, fincas rústicas en varios municipios y era un comerciante mayorista que hacia las funciones de agente financiero de Banamex.

\section{LIMITACIONES TÉCNICAS DEL OTORGAMIENTO DE CRÉDITO}

De acuerdo con la Ley de 1897, el BCh tenía la facultad de otorgar créditos pero las normas limitaban su autorización, las políticas insertas en la legislación restringían la realización de estas operaciones, ya que en el articulo 29, apartado I establecía: «Queda prohibido a los Bancos de Emisión: I. Hacer operaciones de préstamo y descontar o negociar documentos de crédito, cuando el plazo del vencimiento pase de seis meses». ${ }^{43}$ Esta disposición no era congruente con la política oficial, puesto que se requería impulsar 
proyectos provechosos pero este artículo los frenaba. Ningún plan agrícola o ganadero, sin hablar ya de los industriales, podría en este corto tiempo hacer una proyección de inversión, ni hacer rentable ningún negocio o empresa con este tipo de política. La producción chiapaneca era agrícola-ganadera, los seis meses otorgados para la liquidación de los créditos no era tiempo suficiente para obtener los resultados esperados por obvias razones. Aunque esto no era un problema, ya que por lo regular se tramitaban constantes renovaciones de los créditos otorgados, desvirtuando así las políticas oficiales.

La idea que en 1901 tenía cierto sector de la población chiapaneca acerca del funcionamiento de una institución crediticia y los beneficios que le podría brindar, era la que expresaba en su oportunidad La Revista de Chiapas, al señalar que «dicha institución podría acarrear facilidades y ventajas al comerciante, al agricultor, al industrial y al simple ciudadano». ${ }^{44}$ Esta idea se basaba en que al banco se le veía como el promotor del progreso, que llevaría al estado una mejora dando apoyo a los inversionistas y permitiendo con esto que fuera efectiva su inserción en el mercado nacional e internacional. Aparte de la limitante reglamentaria de seis meses, ${ }^{45}$ también se tenían las de orden interno, el propio banco fijaba sus políticas aduciendo que los créditos deberían otorgarse apegándose a los siguientes parámetros:

\begin{tabular}{lc}
$\frac{\text { Monto }}{\text { De } \$ 20,000.00 \text { o más }}$ & Tasa de Interés. \\
\cline { 2 - 2 } $\begin{array}{l}\text { De } \$ 00.00 \text { a } \$ 19,999.99 \\
\text { De } \$ 201.00 \text { a } \$ 499.99\end{array}$ & $10 \%$ \\
No hay créditos menores de $\$ 200.00^{46}$ & $15 \%$
\end{tabular}

Esta política estaba en contradicción con las necesidades de desarrollo puesto que eran los productores de bajos ingresos la parte más numerosa de la población; la propiedad de las tierras estaba concentrada en pocas manos y era muy frecuente encontrar a pequeños agricultores que trabajaban las tierras de los finqueros en pago por el arrendamiento de las mismas. Muchas veces, la gente que no tenía los medios suficientes para garantizar un crédito recurrían a los agiotistas, quienes se enriquecían con esta práctica; tal fue el caso de los españoles Pedro del Cueto en Tuxtla Gutiérrez y de José Revuelto en Tapachula. Pero no eran los únicos, había personajes y organizaciones nacionales y extranjeras que, al 
detectar las deficiencias de la Ley General de 1897, efectuaban estas funciones, como se puede apreciar en el siguiente cuadro:

\section{Cuadro 2. Pormenor de las Escrituras Públicas inscritos en el Registro de la Propiedad del Departamento de Soconusco en $1905 .{ }^{47}$}

\begin{tabular}{|c|c|c|c|c|c|}
\hline Acreedor & Deudor & $\begin{array}{l}\text { Valor del } \\
\text { crédito }\end{array}$ & $\begin{array}{c}\text { Fecha de } \\
\text { registro }\end{array}$ & Garantía & Moneda \\
\hline $\begin{array}{l}\text { Banco de Occidente de } \\
\text { Guatemala }\end{array}$ & Rufino Ibarguen & $158,198,00$ & feb-16 & Hipotecaria & $\begin{array}{l}\$ 79,099.00 \\
\text { oro } \\
\text { americano } \\
\end{array}$ \\
\hline Antonio Lango & Manuel Rosas & $1,700,00$ & may-15 & Hipotecaria & Cachuca \\
\hline Adolfo Giesemann & Manuel Bejarano & $6,071.12$ & may-22 & Hipotecaria & Cachuca \\
\hline $\begin{array}{l}\text { Liegmund Rowinow y } \\
\text { John de Hamburgo }\end{array}$ & Oliverio Harrison & $149,500,00$ & may-29 & Hipotecaria & $\begin{array}{l}\$ 299,000.00 \\
\text { marcos }\end{array}$ \\
\hline $\begin{array}{l}\text { Coterweth y Powell de } \\
\text { Londres }\end{array}$ & Francisca A. Vda. de & $67,380,00$ & abr-05 & Hipotecaria & \begin{tabular}{|l|}
$6,738.00$ \\
Libras \\
Esterlinas
\end{tabular} \\
\hline $\begin{array}{l}\text { Maegli Gaengant de } \\
\text { Hamburgo }\end{array}$ & Jacobi y finca & $60,000,00$ & jun-13 & Hipotecaria & $\begin{array}{l}\$ 120,000.00 \\
\text { marcos }\end{array}$ \\
\hline José Revuelto & José de la Campa & $4,800,00$ & abr-05 & Hipotecaria & Mexicana \\
\hline $\begin{array}{l}\text { Sociedad Brillasca } \\
\text { Hermanos }\end{array}$ & Federico Alonso G. & $12,000,00$ & jun-15 & Hipotecaria & Mexicana \\
\hline $\begin{array}{l}\text { Cía. Mexicana de } \\
\text { Terrenos y Colonización }\end{array}$ & Ramón Armendáriz & $3,400,00$ & jul-11 & Hipotecaria & Mexicana \\
\hline Adolfo Giesemann & Luis Labala & $1,042.56$ & ago-10 & Hipotecaria & Mexicana \\
\hline $\begin{array}{l}\text { María del Rosario } \\
\text { Suárez }\end{array}$ & $\begin{array}{l}\text { Manuel Sánchez de } \\
\text { León }\end{array}$ & 8720,00 & oct-05 & Hipotecaria & Mexicana \\
\hline Fernando J. Braun & Ricardo L. Bado & $6,000,00$ & nov-21 & Hipotecaria & Mexicana \\
\hline Benito Zabuada & $\begin{array}{l}\text { Hidalgo Plantation le } \\
\text { Comercial }\end{array}$ & $43,445,00$ & nov-21 & Hipotecaria & Mexicana \\
\hline
\end{tabular}

De los datos del cuadro anterior se deduce que la obtención de recursos crediticios en la región no fue un obstáculo, el flujo de capitales permitió a los finqueros más prominentes y a las agencias extranjeras allegarse fondos para hacer rentables sus unidades productivas en fincas cafetaleras, cacaoteras, de extracción del hule, de maderas preciosas. Pero las inversiones en tecnología eran mínimas. 
La práctica del agiotismo muchas veces no se reportaba como una actividad profesional de agentes de bolsa, de crédito o funcionarios bancarios, simplemente efectuaban estas operaciones de manera tan natural sin dar cuenta de este trabajo. Tan fue así que después de haber servido de fuente de recursos para los empresarios de la localidad -refiriéndome a los inversionistas extranjeros y nacionales- eran buscados para que pagasen los impuestos que estas operaciones les habían generado; basta ver que a Enrique Hermann y a los señores Herman Schroeder la Colecturía de Rentas del Soconusco les notificaba las multas a que habían sido acreedores por no haber manifestado las operaciones bancarias que habían realizado, fijándoles a ambos una multa de ciento cincuenta pesos por no haberlas reportado a esa dependencia. ${ }^{48}$ Esta práctica fue constante y se presentó en todo el estado; tan es así que en 1916 el general Blas Corral, en el Informe que le rindió al ministro de Gobernación, hacía mención de que en la ciudad de Chiapa de Corzo se habían presentado varios vecinos quejándose por:

que las señoras Natividad, Fortunata y Cleotilde Gómez les han facilitado algunas cantidades de dinero en calidad de préstamo por las que han dado en garantía escrituras de venta absoluta de sus fincas urbanas y por cuyas cantidades han pagado a estas, intereses que exceden en mucho del tipo legal y algunas han satisfecho mayores réditos que el capital recibido. ${ }^{49}$

Reclamaciones como estas se presentaron en varias zonas del estado, por lo que las fuerzas carrancistas tomaron la decisión de dictar una ley que liberara a las propiedades que su gravamen no fuera arriba de tres mil pesos, evitando con esto que los prestamistas cometieran otras anomalías y se aprovecharan de la necesidad de la población. ${ }^{50}$ Esta fue la razón por la que se decretó la ley que declaraba la nulidad radical de las operaciones de retroventa cuando el valor no excediera de tres mil pesos, «cantidad que obedece a los conceptos más rigurosos del orden jurídico; la cuota de tres mil pesos reconoce como fundamento, el carácter que ostenta dicha ley de ser completamente protectora de los proletarios que solo alcanzan a esa suma según los usos del Estado». ${ }^{51}$ 


\section{LA CIRCULACIÓN DE LA MONEDA «CACHUCA» EN EL ESTADO}

Desde que se integraron a la república mexicana Chiapas y Soconusco, en 1824 y 1842 respectivamente, la moneda que circulaba en la entidad era la «cachuca»; ${ }^{52}$ esta práctica se mantuvo en gran parte del estado hasta 1920, fecha en que concluyó oficialmente la Revolución mexicana y el nuevo gobierno buscaba establecer un banco central que regulara la emisión de la moneda en el país. ${ }^{53}$ La escasez de numerario oficial en Chiapas durante el porfiriato propició que fuera utilizada la moneda extranjera en el estado en todas las operaciones comerciales que se realizaban en la entidad, ${ }^{54}$ aun las del comercio de menudeo. No podía ser de otra manera, la lejanía con el centro de la República, la falta de caminos y vías adecuadas para llevar a los mercados del interior los productos destinados a la exportación les dificultaba obtener moneda acuñada de curso legal; pero además, en el caso de que pudieran conseguirla, había que comprarla a sus poseedores pagando una prima o comisión que fluctuaba entre «30 y 35\% para obtenerla», ${ }^{55}$ razón por la cual la población prefería utilizar la moneda «cachuca», porque no presentaba ninguna clase de restricciones y era aceptada por la población.

Las razones del porqué la moneda «cachuca» se había afianzado en el estadoeran varían, siendo la primera de ellas de orden histórico. Los vínculos de origen y afinidad que desde épocas remotas había mantenido Chiapas con Guatemala habían sido un baluarte para seguir manteniendo las ligas comerciales entre ambas entidades. Chiapas, alejado como estaba de los centros con actividad industrial, comercial y agrícola del interior de la República, tenía la necesidad de exportar sus productos a la nación vecina del sur; por esta situación los productos generados en los departamentos fronterizos se comercializaban en los países centroamericanos donde encontraban compradores de manera segura. El estado exportaba a Guatemala ganado mayor y de toda clase que colocaba en las ferias centroamericanas, además de licores y artículos de primera necesidad. La separación de Chiapas y Guatemala afectó muy poco las relaciones comerciales entre las dos comarcas ya que subsistían las identidades de raza, lengua y religión; por lo mismo el comercio entre ambas siguió desarrollándose de manera natural. 
Guatemala era un país esencialmente agrícola, carecía de productos que pudieran comercializarse en el mercado chiapaneco pues no habían diversificado su economía. Esta situación, aunada a que su sistema financiero no contaba con la debida solidez para comercializar en el extranjero, obligaba a los exportadores chiapanecos a aceptar en pago de sus productos su moneda, ya que su sistema de giros sobre el extranjero era muy inestable y por lo mismo se volvía riesgoso recibirlos para cubrir sus adeudos. Así lo manifestó un periódico local cuando señalaba que el «mercado de cambios en Guatemala, que era muy variable, ocasionaba que en su régimen de papel moneda se registraran diferencias hasta de 50 y aún de 100 puntos un mismo día». ${ }^{56}$ La fragilidad del sistema financiero guatemalteco provocó que circulara en su mercado interno monedas de otros países, como los antiguos pesos chilenos, los soles peruanos y hasta la moneda colombiana, que llegaba desde Europa ${ }^{57}$ invadiendo así el estado chiapaneco y circulando con grandes riesgos. Esta era aceptada en la localidad, aun bajo la advertencia que había manifestado en 1901 un reporte periodístico que daba a conocer la situación de los bancos centro y sudamericanos, señalando el peligro que representaba aceptar sus billetes como moneda buena cuando estos no tenían un soporte metálico que garantizara su circulación:

En efecto, por los siguientes datos tomados de las memorias que algunos bancos rindieron en el primer semestre del corriente año, pueden ver nuestros lectores, que no son exageradas las apreciaciones que hacemos.

\begin{tabular}{|l|r|r|r|}
\hline & & \multicolumn{1}{|l|}{ Billetes } & \multicolumn{1}{l|}{ Billetes } \\
\hline Bancos & Metálico & Existencia & \multicolumn{1}{|c|}{ En Circulación } \\
\hline Internacional & $\$ 83,101.47$ & $\$ 273,872.00$ & $\$ 4,052,758.00$ \\
\hline Hipotecario & $\$ 238,481.37$ & $\$ 943,512.00$ & $\$ 1,920,767.00$ \\
\hline Americano & $\$ 332,360.43$ & $\$ 1,120,392.00$ & $\$ 298,073.00$ \\
\hline De Guatemala & $\$ 146,801.73$ & $\$ 1,018,244.00$ & $\$ 6,161,558.00$ \\
\hline De Occidente & $\$ 23,879.97$ & $\$ 963,447.00$ & $\$ 317,808.00$ \\
\hline Comité Bancario & Nada & Nada & $\$ 6,000.000 .00$ \\
\hline Total: & $\$ 824,624.97$ & $\$ 4,319,467.00$ & $\$ 18,750,964.00$ \\
\hline
\end{tabular}

Resulta pues, que tienen $\$ 824,624.97$ cts. Plata por $\$ 23,070,431.00$ cts., en billetes, excluyendo el ‘Banco Colombiano’ cuya memoria no conocemos y en el que es de suponer haya también mayor cantidad de billetes que plata, haciendo punto omiso del níquel en circulación que se calcula en seis millones de pesos. ${ }^{58}$ 
Aunque no se tiene la certeza de la veracidad de las cifras, era de suponerse que no estaba tan alejado de la realidad puesto que los bancos centro y sudamericanos tenían problemas de financiamiento con instituciones y casas comerciales extranjeras, específicamente las europeas y norteamericanas; pero a pesar de que los productores y comerciantes de Chiapas tenían conocimiento de la fragilidad con que se manejaba el sistema financiero guatemalteco asumían el riesgo de pérdida en caso de que se declaran dichas instituciones en quiebra, porque la emisión de su moneda fiduciaria no contaba con el respaldo metálico para cubrir su circulación al momento de hacer efectivo su importe, no así la acuñada, que por sí misma tenía su propio valor en plata.

Llegó a pensarse en algún momento que esta situación era consecuencia de la falta de un banco local que sirviera de intermediario para efectuar los cambios de esta moneda. Pero la realización de los cambios por sí sola no era la solución. El hecho era que mientras la población chiapaneca aceptara como buena esta moneda, podía seguir dominando el mercado, lo cual era claro porque, mientras los exportadores de Chiapas prefirieran aceptar los pagos de sus transacciones comerciales con moneda «cachuca», no podría ser fácilmente expulsada del territorio ni ser enviada de regreso a su país, y que: «Generalmente el ganadero chiapaneco que ha ido a las ferias conduciendo el mismo sus partidas, regresa a su tierra natal llevando a lomo de mula las monedas que sirvieron de precio al ganado». ${ }^{59}$

La moneda «cachuca» se introduce a Chiapas a través del comercio en pago de las importaciones. Se recibe como una mercancía que se cambia por otras mercancías y los comerciantes de Chiapas, así como los compradores guatemaltecos, prefieren hacer este tipo de intercambio que negociar con giros sobre el extranjero; aunque esta última operación podría ser más confiable para ambas partes, pero decidieron no utilizarlo porque existía una preferencia especial para recibir los pagos en 'cachuco', predilección que se puede explicar por el hecho de que tal moneda, aparte de ser aceptada sin dificultad en el estado, solía dejar ganancias considerables a los financieros y comerciantes locales:

El exportador chiapaneco, que realiza sus operaciones en Guatemala, se ha visto en el caso de elegir, en aquel mercado, entre cobrar el precio de sus exportaciones en 
giros, o cobrarlo en la moneda «cachuca». Ha preferido lo que le resulta más cómodo y más lucrativo. Si cobraba en giros, en efecto, estos no podían ser directos sobre Chiapas, sino en raros casos, ya que Guatemala rara vez tiene saldos en su favor en poder de los banqueros de Chiapas. Tenían que ser, entonces, giros sobre México o sobre algún mercado europeo o norteamericano; pero como los giros sobre México son escasos en Guatemala, y lo han sido más aún en épocas anteriores, el exportador chiapaneco se veía precisado a aceptar las letras sobre Londres o sobre Nueva York, para venderlas en Chiapas. Si optaba por venderlas contra moneda 'cachuca', perdía la diferencia entre los precios de compra y los de venta de los giros; si los vendía por moneda mexicana se encontraba con especies que carecían de circulación en el lugar y que tenía que volver a negociar, acaso con pérdida. Todo esto hubo de decidirle, como era natural, a efectuar el cobro en «cachuco», tanto más que el transporte le resultaba casi gratuito, ya que para efectuarlo no tenía sino cargar sus propias acémilas. ${ }^{60}$

Del total de la moneda «cachuca» que ingresaba a Chiapas, una parte de ella se quedaba circulando en el estado, la otra era exportada por los comerciantes para ser vendida en los mercados de Estados Unidos o de Europa por la cantidad de plata pura que contenía, y finalmente el resto se enviaba a Guatemala para realizar operaciones especulativas, que les redituaban grandes beneficios, y es que: «sabese en aquel país que los cambios descienden invariablemente en determinada época en que los productores de café venden sus giros sobre el extranjero, por la abundancia de letras que hay entonces en el mercado, y que vuelven a subir tan pronto como pasa esa época. ${ }^{61}$ Eran estas las oportunidades que aprovechaban los especuladores chiapanecos para devolver la moneda «cachuca», ya fuera en metálico o en billetes, a su lugar de origen y con lo obtenido compraban oro en buenas condiciones. $^{62}$ Pero esto traía consecuencias que se reflejaban en la emisión del papel moneda ante la exigencia de canjearlos por moneda acuñada, lo cual provocó que el papel moneda de Guatemala comenzara a disminuir por no tener el soporte en metálico para operar compras en el extranjero. La injerencia de esta moneda en el mercado local se ponía de manifiesto en un reportaje que había publicado El Heraldo de Chiapas, en 1907, dando a conocer parte del territorio chiapaneco que dominaba, de lo cual daba cuenta un hombre de negocios de Tuxtla, quien relataba el estado «incomprensible», inconveniente e insostenible de la situación monetaria en Chiapas. ${ }^{63}$ Esta crónica es muy elocuente, porque 
deja en claro cuál era el papel del numerario nacional y cómo se anteponía el «cachuco» en todas las operaciones mercantiles:

Tomando rumbo a San Cristóbal, [sic] hasta Ixtapa, observaremos que circula, se exige y se paga en plata mexicana. Hasta ahí llega el dominio de nuestras águilas. Ya en el Burrero, a diez kilómetros de Ixtapa, comienza el reino de su majestad el «cachuco», pero en que términos. Los precios están calculados sobre la base de llamarse peso una moneda ilusoria, ideal, equivalente a un peso fuerte «cachuco» más 6 y cuarto centavos mexicanos (medio real) es decir, que si tenemos que pagar o recibir cien pesos, entregamos o nos dan «cachucos» fuertes y 100 medios reales mexicanos, o, según la costumbre ya establecida, entrega o pagan a razón de diez y seis «cachucos» por quince pesos (ideales) mexicanos, porque esos diez y seis «cachucos» no valen los quince pesos mexicanos positivos. ${ }^{64}$

La crisis financiera de 1900 de los Estados Unidos de Norteamérica afectó seriamente la economía guatemalteca, por ser su dependiente directa, lo mismo que los países sudamericanos. Esta inestabilidad económica se había convertido en una seria amenaza para los productores de Chiapas. El desequilibrio económico se mantuvo hasta ya muy entrado el siglo XX. El «cachuco» que circulaba en el mercado local llegó a utilizarse para medir el valor de la moneda nacional en lugar de que sucediera lo contrario, derivado del interés por la obtención de ganancias.

En alguna ocasión el gobierno federal le había concedido cierto valor legal a la moneda «cachuca» admitiéndola como buena para realizar pagos de contribuciones, por la carencia de numerario nacional para realizarlos en la localidad. Este hecho acreditó al «cachuco» ante la población para considerar buena esta moneda y se prolongó hasta 1917, en que la administración federal empezó a controlar la emisión de la moneda nacional. Un ejemplo de la importancia que tenía el «cachuco» en la localidad se presentó cuando la elite sancristobalense protagonizó el levantamiento armado de 1911, ${ }^{65}$ enarbolando la bandera maderista en contra de los tuxtlecos y desconociendo al gobierno de Manuel Rovelo Arguello por considerarlo miembro de la camarilla rabasista. El 6 de julio de 1911, Manuel Pineda lanzó un decreto donde hacía alusión a la utilización del «cachuco» argumentando las dificultades para adquirir moneda nacional para realizar el pago de contribuciones y proponía que se utilizara la moneda cachuca. ${ }^{66}$ 
Los bancos de Chiapas y Nacional de México se habían propuesto expulsar la moneda «cachuca» del estado, porque la consideraban como cualquier mercancía, pero sus esfuerzos fueron nulos, al igual que el de los de Rafael Pimentel, gobernador de Chiapas en $1901,{ }^{67}$ quien había decretado que no se utilizara dicha moneda, pero no se pudo efectuar dicha disposición. No existía numerario nacional suficiente para hacer frente a las necesidades en la entidad. La idea era desalojarla sin que estas medidas trastornaran la economía o llegase a presentar pérdidas a los tenedores ni a perturbar la marcha de los negocios. Pero lo obvio era que mientras esta moneda pudiera ingresar sin ninguna dificultad al estado, sería muy difícil impedir su importación, ya que los comerciantes chiapanecos que comercializaban con Guatemala: «seguirán prefiriendo traer el «cachuco» en especie, porque de esta manera se mantenían en el juego de las especulaciones a que se presta el comercio con esta moneda», ${ }^{68}$ que les había dado buenos dividendos.

Una de las medidas para que la moneda «cachuca» no ingresara al estado era el aplicarle un gravamen del 15 por ciento antes de realizar las operaciones a los compradores guatemaltecos, tratando de evitar que no tuviera un campo de acción más amplio en la entidad, pues se creía que los comerciantes del vecino país del sur lo pensarían antes de concertar sus operaciones mercantiles con los productores locales. Muchos habían sido los intentos para que esta moneda no penetrara al estado, pero todos habían sido infructuosos, a tal grado que un periódico local había hecho algunos señalamientos sobre esta cuestión, justificando la aplicación de este impuesto puesto que no tenía razón de ser que dicha moneda circulara en la entidad como medida de valor, ya que muchas otras ya no se utilizaban en sus países de origen: «Las monedas chilenas, peruanas, etc., a que nos referimos no son más que simples barras de plata, sobre las cuales se puede cobrar un impuesto, como se cobra sobre la plata que se produce en el territorio». ${ }^{69}$ Dicha propuesta se había considerado porque la legislación guatemalteca prohibía la exportación de plata acuñada; de esta manera la ley mexicana cooperaría en la aplicación de la ley guatemalteca y obligaría a suspender inmediatamente la importación del «cachuco» y cerraría «la fuente de donde nos viene esa moneda espuria y nos ayudaría a acostumbrar al pueblo chiapaneco el uso exclusivo de la moneda nacional». ${ }^{70}$ Propuesta que no fructificó. 
Otra propuesta fue que los bancos se pusieran de acuerdo con el gobierno federal y con la administración estatal para comprar la moneda a un precio similar al de la plata, añadiéndole los gastos que pudieran realizarse en su procesamiento; es decir, recogerla a fin de convertirla en pasta de plata que podría ser vendida con ventaja en los mercados extranjeros. Esta medida ofrecía pocas dificultades; el caso es que la mayor parte se encontraba en manos de capitalistas que no querían perder los beneficios que de ella obtenían en sus transacciones. También se propuso recibirla por un tiempo en el pago de impuestos locales y venderlas a su vez a la Federación. ${ }^{71}$ Esta propuesta de venderla en los mercados internacionales era una alternativa viable para evitar que dicha moneda siguiera circulando fuera de sus países de origen. Así los tenedores de este metal, que eran los comerciantes chiapanecos, que mantenían en su poder grandes cantidades de este numerario, realizaron operaciones de venta obteniendo muy buenos resultados, porque:

[...] aprovechando las excepcionales circunstancias que ofrece en la actualidad el alza de la plata, se haga una combinación entre la Comisión de Cambios y Moneda, los bancos nacionales y de Chiapas y el Gobierno del Estado, para comprar el «cachuco» y exportarlo, sustituyéndolo con la moneda mexicana. A ese respecto nos ilustra refiriéndonos que recientemente la casa de G. Amsick y C., acaba de vender en Nueva York, 10,000 «cachucos» a 49 1⁄2 centavos de dólar, lo cual nos parece una operación fructuosa. Si se aprovechan las actuales circunstancias, puede convertirse el «cachuco» circulante en Chiapas, en moneda mexicana de oro, casi a la par. ${ }^{72}$

Aunque si bien es cierto que seguía en circulación la moneda guatemalteca, era a causa de la lejanía que tenía esta región con respecto al centro de México para comercializar de manera directa; que era más fácil hacerlo con Guatemala, donde se utilizaban los puertos para dar salida a los productos chiapanecos. Inserto como estaba el estado en el mercado capitalista, era menester contar con una moneda que respaldara sus operaciones haciendo más apremiante que se contara con un medio de cambio que evitara dificultades en su manejo al efectuar los pagos que habían de ocuparse en la realización de las operaciones 
financieras; ya que la moneda representaba un papel importante en todas las transacciones comerciales habría de procurar que fuera la mejor posible;

\begin{abstract}
Hay una gran región en Chiapas compuesta de los Departamentos de San Cristóbal, Comitán, Chilón y Mariscal que usan la moneda Centro y Sud-Americana llamada «cachuca», que tantas y tan graves dificultades presenta en los cambios. Estas monedas que ya no son usadas en algunas naciones a las que antes pertenecieron, todavía circulan en los departamentos arriba mencionados, siendo un gran obstáculo, puesto que, para efectuar las transacciones con los demás mercados, es necesario cambiarla por moneda nacional, y como esta por consecuencia de la ley Gresham, es sumamente escasa, además de las grandes dificultades que se encuentran para su cambio, los premios enormes que se pagan vienen a formar, en cantidades más o menos grandes, una pérdida considerable. ${ }^{73}$
\end{abstract}

Por eso, era necesario que dicha moneda fuera sustituida por la de curso legal del país. Para estas fechas el Soconusco ya había sustituido la moneda «cachuca», por considerarla depreciada, pero además porque muchas fincas les pagaba a los trabajadores con vales que ahí expedían y eran canjeados en las tiendas que ahí funcionaban; esto les facilitó expulsar a la moneda invasora. Para 1912 se seguía haciendo la propuesta a la Federación Mexicana para que utilizara todos los medios posibles para lograr la unificación del sistema monetario, porque solo en Chiapas circulaba una moneda extranjera como numerario de curso legal. Emilio Araujo, articulista que había publicado estas notas, se refiere a la Ley de Gresham $^{74}$ bajo la óptica de explicar la dificultad que existía en la región para la adquisición de la moneda nacional y la urgencia que se tenía para subsanar esta situación, pero esta solo se presentó cuando que se efectuó una reglamentación nacional en 1917 y se aprobó la Constitución Mexicana, producto de la gesta revolucionaria que encabezó Venustiano Carranza con su ejército constitucionalista.

\title{
CONCLUSIÓN
}

De esta manera concluye la historia de un banco que se estableció en territorio chiapaneco, al que se denominó Banco de Chiapas y que pretendía tener un «monopolio plural» en la entidad, en cuyo lugar no podían circular otros billetes que no fueran los que ellos emitían 
y tampoco se podía instalar otra institución de la misma naturaleza que le impidiera cumplir con su cometido. Tendría que ser un banco comercial que impulsara el desarrollo de la entidad, pero por diversas causas no pudo afianzarse ni tener presencia en una región que presentaba altos grados de pobreza y marginación. La existencia de una gama de empresarios-financieros que se habían arraigado en la entidad de alguna manera limitó su funcionamiento; eso, aunado a la carencia de una clase media que fuera el motor de la sociedad, originó su decadencia. El estado contaba con una población mayoritaria de indígenas, mozos y baldíos que no servían como un soporte económico que elevara los ingresos de esta institución. Pero también se enfrentó a una competencia fuerte con la moneda cachuca que circulaba en la entidad como si fuera de curso legal. Muchos fueron los factores que determinaron la fusión de esta institución con el BOM, dando por terminadas las aspiraciones que habían albergado en algún momento los inversionistas del BCh y que terminaron opacando su actividad y sus acciones.

Después de 1909, el BCh se convirtió en una sucursal del BOM que siguió operando en la entidad. El BOM desapareció en 1915, después del estudio que el gobierno revolucionario realizó a los bancos del país, detectando que las cifras que presentaba dicha institución eran maquilladas, que se había excedido en la emisión de papel moneda, y que el soporte en metálico no cubría dicha cantidad ya que en depósitos y billetes en circulación tenía $\$ 27^{`} 992,799.00$, contra existencias en metálico por $\$ 6{ }^{\prime} 238,189.00 .^{75}$ De esta manera el gobierno carrancista decidió declararle la caducidad de la concesión para seguir operando. 


\section{BIBLIOGRAFÍA}

Benjamin, Thomas Louis, 1990, El camino a Leviatán, Chiapas y el Estado mexicano, 1891-1947, CONACULTA, México.

Cardoso, Ciro (coordinador), 1982, México en el siglo XIX (1821-1910). Historia económica y de la estructura social, Ed. Nueva Imagen, $3^{a}$. Edición, México.

Casahonda Castillo, José, 1963, Cincuenta años de revolución en Chiapas, ICACH, Chiapas, México, $1^{\text {a }}$ Ed.

Espinosa, Luís, 1993, Rastros de sangre. Historia de la revolución en Chiapas, $4^{\mathrm{a}}$ Ed. Instituto Chiapaneco de Cultura, Gobierno del Estado de Chiapas.

Foucault, Michel, 1968, Las palabras y las cosas. Una arqueología de las ciencias humana, Ed. Siglo XXI, Argentina.

Gamboa Ojeda, Leticia, «De dependencia e insolvencia: El banco de Oaxaca, 19021909»,http://codex.colmex.mx:8991/exlibris/aleph/a18_1/apache_media/XCEP53FDI1B1J KQ3VJAACDL859284G.pdf (consulta 03-03-2011).

Katz, Friedrich, 2008, La guerra secreta en México. Europa, Estados Unidos y la Revolución Mexicana, Ed. ERA, 7ª Reimp., 1 Tomo, México.

Manero, Antonio, 1957, La revolución bancaria en México. Una contribución a la historia de las instituciones de crédito en México, Ed. Somex-Miguel Ángel Porrúa, México, 1957.

Molina Pérez, Valente, 2006, Por los rieles de Chiapas. Construcción del Ferrocarril Panamericano, Ed. Gobierno de Chiapas, Asociación de Cronistas del Estado de Chiapas, A.C., Sistema Chiapaneco de Radio y Televisión, Canal 10. 
Molina Pérez, Valente, 2011, El Banco de Chiapas (1902-1914). Pionero en Tuxtla, Ed.

Asociación de Cronistas del Estado de Chiapas, A.C.

Zebadúa, Emilio, 2001, Breve historia de Chiapas, Fideicomiso Historia de las Américas, Serie Breves Historias de los Estados de la República Mexicana, 2a Reimp., Ed. FCEColmex.

\section{ARCHIVOS}

Archivo General de la Nación:

Fondo: Gobernación Periodo Revolución.

Fondo: Antiguos Bancos de Emisión.

Archivo histórico del estado de Chiapas.

Sección Hacienda, Hemeroteca Fernando Castañón Gamboa.

Documentos impresos:

Memorias, Informe de Gobierno de Rafael Pimentel, 1901. Imprenta del Estado.

Memorias, Informe de Gobierno de Rafael Pimentel, 1902. Imprenta del Estado.

Memorias, Informe de Gobierno de Rafael Pimentel, 1905. Imprenta del Estado.

Memorias, Informe de Gobierno de Ramón Rabasa, 1908. Imprenta del Estado.

Memorias, Informe de Gobierno de Ramón Rabasa, 1910. Imprenta del Estado.

Artículos:

AHECH, El Heraldo de Chiapas, Tuxtla Gutiérrez, agosto 28 de 1906, Año 1, No. 8.

AHECH, El Heraldo de Chiapas, Tuxtla Gutiérrez, enero 15 de 1907, Año 1, No. 28.

AHECH, El Heraldo de Chiapas, Tuxtla Gutiérrez, septiembre 18 de 1906, Año 1, No. 11.

AHECH, El Heraldo de Chiapas, Tuxtla Gutiérrez, febrero 3 de 1907, Año 1, No. 31.

AHECH, El Heraldo de Chiapas, Tuxtla Gutiérrez, diciembre 18 de 1906, Año 1, No. 24.

AHECH, El Heraldo de Chiapas, Tuxtla Gutiérrez, diciembre 25 de 1906, Año 1, No. 25.

AHECH, El Heraldo de Chiapas, Tuxtla Gutiérrez, enero $1^{\circ}$ de 1907, Año 1, No. 26. 
AHECH, El Heraldo de Chiapas, Tuxtla Gutiérrez, enero 8 de 1907, Año 1, No. 27.

AHECH, FFCG, Revista de Chiapas, agosto 31 de 1902, Núm. 1, p. 2.

AHECH, El Clavel Rojo, Tomo I, Comitán, 31 de agosto de 1902, No. 1.

AHECH, El Clavel Rojo, Comitán, 29 de septiembre de 1901, T. 1, Núm. 7.

AHECH, La voz de Chiapas, Año 1, San Cristóbal Las Casas, julio 09 de 1911, Núm. 25

AHECH, Periódico Oficial L-18, agosto 30 de 1902, Tomo XIX, Núm. 35, pág. 7

AHECH, Periódico Oficial, No. 8 del 23 de febrero de 1907.

AHECH, Periódico Oficial, Tuxtla Gutiérrez, abril 14 de 1906, Tomo XXIII, Núm. 15.

AHECH, Periódico Oficial, 27 de enero de 1906, T-XXIII, Núm. 4,

AHECH, Periódico Oficial. Balance practicado el 31 de diciembre de 1905. Ref. Libro 27

AHECH, HFCG, Diario de Chiapas, 31 de agosto de 1912.

AHECH, FFCG23. T1, V. Datos del anuario estadístico de 1908, T. I, Núm. 1.

AHECH, Fondo Hacienda, Tomo I, 1908.

AGN, Acervo Antiguos Bancos de Emisión, Fondo del Banco de Chiapas. Caja 2082, LS/N, Año 1906.

AGN, Grupo Documental: Fondo Revolución, Sección Rev. y Régimen Maderista. E-52, C-1, Fs. 15. Francisco Cosío Rovelo, designado por Francisco I. Madero para analizar el origen del levantamiento de 1911.

AGN, Gobernación Periodo Revolucionario: Informe de Blas Corral, 1915, Vol. 61, Exp. 10, pp. 44-45.

AGN, Ley General de Instituciones de Crédito, 19 de marzo de 1897.

Secretaría de Hacienda y Crédito Público, Memoria de las Instituciones de Crédito, «Concesiones, Estatutos y Documentos Especiales».

\section{NOTAS}

\footnotetext{
${ }^{1}$ Gamboa Ojeda, Leticia, en su libro De dependencia e insolvencia: El banco de Oaxaca, 1902-1909, anota que: Cuatro meses antes -desde comienzos de diciembre de 1908- ya estaba en marcha el plan de fusionar al Boax con el Oriental, y fusionar al mismo tiempo al Banco de Chiapas [sic], que estaba en los mismos apuros, p. 517

${ }^{2}$ De aquí en adelante se le designará Banamex.

${ }^{3}$ Zebadúa, Emilio. Breve historia de Chiapas. 2001. p. 117.
} 
${ }^{4}$ Secretaría de Hacienda y Crédito Público, Memoria de las Instituciones de Crédito, «Concesiones, Estatutos y Documentos Especiales». La concesión para la apertura de la Institución se dio el 25 de septiembre de 1901.

${ }^{5}$ Ley General de Instituciones de Crédito, 19 de marzo de 1897, Capítulo primero, «De las Instituciones de Crédito y de su constitución». Artículo 10.

${ }^{6}$ José A. Bátiz, Enrique Canudas S., en Cardoso, C. México... p. 412.

${ }^{7}$ Gamboa Ojeda, Leticia, «De dependencia e insolvencia...» menciona que: «El sistema bancario porfiriano se fincaba en el principio de la convertibilidad de los documentos fiduciarios (billetes, cheques y demás) por dinero constante y sonante. A menos que el documento expresara otra cosa, este debía ser reembolsado en monedas de curso legal y de manera integra e inmediata. Por lo tanto, los bancos de emisión debían tener en todo el tiempo la capacidad de cumplir con ese principio, cuyo objetivo era infundir la confianza del público en los papeles fiduciarios y en especial en el billete de banco», p. 473.

${ }^{8}$ Ibíd. p. 415.

${ }^{9}$ AHECH, El Heraldo de Chiapas, Tuxtla Gutiérrez, agosto 28 de 1906, Año 1, No. 8. «Tenemos notas en cartera, que nos revelan cómo personas quienes antes del robo no habían depositado ni un peso en los bancos, lo han hecho ya, convencidos objetivamente -pudiera decirse- de que más que en el fondo de un baúl, en el interior de la proverbial calceta, en la usada cartera que sujeta una banda de hule o en cualquier otra parte semejante, en los bancos gozan de grandes seguridades los capitales en numerario».

${ }^{10}$ AHECH, FFCG23. T1, V. Datos del anuario estadístico de 1908, T. I, Núm. 1,

11 AGN. Grupo Documental: Fondo Revolución, Sección Rev. y Régimen maderista. E-52, C-1, Fs. 15. Francisco Cosío había sido designado en 1911 por la Secretaria de Gobernación, para que investigara los motivos que habían provocado el enfrentamiento entre las ciudades de Tuxtla Gutiérrez y San Cristóbal Las Casas en septiembre y octubre de ese año. Para esta fecha prácticamente Francisco I. Madero ocupaba ya la presidencia de la República. Y llegaba a la conclusión de que la desigualdad económica había sido una limitante, pero no eran los sojuzgados ni los marginados los que habían provocado este levantamiento, sino las elites de los Altos, y había dividido a la población de la siguiente manera: Amos y señores, 7\%. Siervos, 80\%. Conductores de mercancías, 5\%. Pequeños agricultores, 4\%. Pequeña industria y comercio, $2 \%$. Empleados, 2\%.

${ }^{12}$ Véase apartado $4^{\circ}$ de este mismo artículo, «La moneda Cachuca».

${ }^{13}$ Ley General de Instituciones de Crédito 1897. El artículo 19 estipulaba que, «El billete de Banco es de circulación enteramente voluntaria, y, por tanto, en ningún caso se considerará como forzosa su admisión por el público».

${ }^{14}$ Erróneamente Thomas L. Benjamin, en: El camino a Leviatán, Chiapas y el Estado mexicano, 1891-1947, anota que el Banco de Chiapas se formó con: «un capital de 500 mil pesos aportado por inversionistas de la ciudad de México». p. 113, pero en realidad se creó con capital norteamericano principalmente y se exhibieron únicamente $\$ 255,000.00$ pesos plata, tal como se detallaba en los balances que se publicaban mensualmente en el Periódico Oficial.

${ }^{15}$ Los Científicos fueron el grupo de intelectuales que impulsaron el proyecto de nación con la venia de Porfirio Díaz y fueron los que se habían enriquecido a costa de los negocios que habían realizado principalmente con la administración federal, la cual les había otorgado ciertas prerrogativas en detrimento de la mayoría de la población.

${ }^{16}$ Molina Pérez, Valente, El Banco de Chiapas: pionero en Tuxtla (1902-1915), p.54.

${ }^{17}$ AHECH, Memoria de gobierno de 1902 de Rafael Pimentel.

${ }^{18}$ Molina Pérez, Valente... (2006), p. 55

${ }^{19}$ Molina Pérez, Valente... (2011), p. 61

${ }^{20}$ Ramón Rabasa nació en Tonalá en 1849, hijo del inmigrante catalán José Antonio Rabasa y la criolla Manuela Estebanell Farrera; creció desde 1855 en el rancho San José en Ocozocuautla; estudió en Inglaterra y Alemania, a su regreso incursionó en el fomento de inversiones y la política. Conocía el manejo de las finanzas y el comportamiento económico de Chiapas desde que regresó de Europa, cuando se dedicó a fomentar inversiones; fue jefe político de Tuxtla por unos meses en 1898 y era influyente entre los adinerados.

${ }^{21}$ Molina Pérez, Valente... (2011), p. 69

${ }^{22}$ AHECH, El Clavel Rojo, Tomo I, Comitán, 31 de agosto de 1902. No. 1.

${ }^{23}$ AHECH, Periódico Oficial. Balance practicado el 31 de diciembre de 1905. Ref. Libro 27 
${ }^{24}$ AHECH, Periódico Oficial, agosto 30 de 1902, p. 7

${ }^{25}$ AHECH, Informe de Gobierno de Rafael Pimentel de 1903, p. 11-12.

${ }^{26}$ La posición del entonces gobernador Pimentel era contradictoria puesto que había rechazado la línea de crédito que le había otorgado el gobierno federal con el Banco Nacional de México, que le permitiría contratar empréstitos para cubrir las necesidades más apremiantes de su administración, pero con la idea de no endeudar al Estado decidió no solicitar dichos créditos, sin embargo sí había aceptado la propuesta de endeudarse con los empresarios financieros que dominaban el escenario en la región. Tenía algunos créditos pendientes de liquidar con Pedro del Cueto, quien era representante del Banco Nacional de México y se había destacado como comerciante, finquero y empresario.

${ }^{27}$ Gamboa Ojeda, Leticia, «De dependencia e insolvencia...», p. 475.

${ }^{28}$ AHECH, Periódico Oficial, No. 8 del 23 de febrero de 1907. El Descuento Español, era otra institución del grupo que encabezaba Manuel Rivero Collada, dueño del Banco Oriental de México,

29 Gamboa Ojeda, Leticia, «De dependencia e insolvencia...» La escritura de fusión de los bancos de Chiapas y Oaxaca en el Oriental se otorgó en la ciudad de puebla el 21 de junio de 1909, después de que se habían celebrado Asambleas Generales el 24 de abril anterior, siendo aprobadas por la Secretaría de Hacienda, estableciéndose así que quedarían como sucursales del Banco Oriental, p. 522.

${ }^{30} \mathrm{Katz}$, Friedrich. La guerra secreta en México. Europa, Estados Unidos y la Revolución Mexicana, p. 50.

${ }^{31}$ AHECH, Periódico Oficial, Tuxtla Gutiérrez, abril 14 de 1906, Tomo XXIII, Núm. 15.

${ }^{32}$ AHECH, Fondo Hacienda, Tomo I, 1908. Enviado el 14 de enero de 1908.

${ }^{33}$ AHECH, El Heraldo de Chiapas, Tuxtla Gutiérrez, septiembre 18 de 1906, Año 1, No. 11. «La Sucursal del Banco Nacional de México, de reciente creación en esta plaza, goza de todo el prestigio de su casa matriz ventajosamente conocida en la República y en el extranjero como la más importante de nuestras Instituciones bancarias, y el Banco de Chiapas, intervenido por el Gobierno Federal, demuestra mensualmente en sus balances la solidez y firmeza de su estado económico».

${ }^{34}$ AHECH, Informe de Gobierno de Ramón Rabasa de 1907, pp. 11-12.

${ }^{35}$ A.G.N. Acervo Antiguos Bancos de Emisión, Fondo del Banco de Chiapas. Caja 2082, L-S/N, Año 1906. «Sello: Enoch Paniagua. Notario Público, República Mexicana-Chiapas. [Escritura] Número trece. En la ciudad de Tuxtla Gutiérrez, Chiapas, México a veinte de febrero de mil novecientos seis. [sic] comparecen los señores Rómulo Farrera Rafael Selvas [sic] con su carácter el primero de Consejero en funciones y el segundo de cajero del Banco de Chiapas [con] los siguientes acuerdos II.- Se establecerá lo más pronto posible una sucursal de este banco en Tonalá y otra en Tapachula. Se nombra el personal de la sucursal de Tapachula de la manera siguiente; Gerente Señor R. O. Stevenson». Cabe señalar que este personaje había sido nombrado vice-cónsul por el gobierno inglés en el estado de Chiapas.

${ }^{36}$ Ibíd.

${ }^{37}$ Inglaterra había designado vice-cónsul a R. O. Stevenson en Tapachula. El Heraldo de Chiapas. Febrero 3 de 1907. Año 1, No. 31. Tuxtla Gutiérrez, Chiapas.

${ }^{38}$ Ibíd.

${ }^{39}$ Erróneamente Thomas L. Benjamin, en: El camino a Leviatán, Chiapas y el Estado mexicano, 1891-1947, anota que: «En 1908 el Banco de Chiapas se fusionó con el banco de Puebla y abrió una sucursal en Tapachula», p. 113. Sí se fusiona pero con el Banco Oriental de México, que tenía su sede en Puebla, de capitalistas españoles; para entonces ya la sucursal de Tapachula tenía cerca de dos años que estaba funcionando.

${ }^{40}$ AHECH, El Heraldo de Chiapas, Tuxtla Gutiérrez, febrero 3 de 1907, Año 1, No. 31, articulo, «Cuerpo Consular».

${ }^{41}$ AGN. Grupo Documental: Fondo Revolución, Sección Rev. y Régimen Maderista. E-52, C-1, Fs. 15. Francisco Cosío Rovelo, designado por Francisco I. Madero para analizar el origen del levantamiento de 1911, menciona en su informe que: «Como otra justificación para el acto de Rabasa, cuentan que estando los poderes en San Cristóbal Las Casas en cierta ocasión el gobierno necesitó dinero y no consiguió después de muchos esfuerzos sino una cuarta parte de lo solicitado, y que habiendo ocurrido a Tuxtla Gutiérrez, los comerciantes de esa le dieron todo lo que solicitó dejando caja abierta para lo porvenir, hecho que determinó el más violento traslado». Espinosa, Luis, Rastros de sangre. Historia de la revolución en Chiapas, dice: «El señor Rabasa, al llegar a San Cristóbal Las Casas, antigua capital de Chiapas tuvo un disgusto con la sociedad de esta población, y por tal motivo decidió que fuera la capital del estado Tuxtla, donde él podía medrar con gran facilidad, en bien propio y en el de sus amigos. De estos citaré a ustedes a un tal Rancé y a 
un tal Cueto, que prosperaron a la sombra de Rabasa y se enriquecieron», p. 43. También José Casahonda Castillo, en su libro Cincuenta años de revolución en Chiapas, hace referencia a este hecho: «Por tradición oral se informa: que el régimen de Rabasa urgido de numerario, solicitó un préstamo al comercio lascanense y este -en forma por demás agria- se lo negó. Don Emilio ocurrió entonces al comercio de Tuxtla y a vuelta de mula, uno solo de los comerciantes tuxtlecos, el español Pedro del Cueto, le remitió la cantidad solicitada con el atento recado de que si 'necesitaba otra cantidad igual o mayor que avisara para enviársela», p. 12.

42 AHECH, Informe de Gobierno de Rafael Pimentel de 1902, pp. 11-12.

${ }^{43}$ Ley General de Instituciones de Crédito de 1897.

${ }^{44}$ AHECH, FFCG, Revista de Chiapas, agosto 31 de 1902, Núm. 1, p. 2.

45 AGN, Ley General de Instituciones de Crédito de 1897, Artículo 29. Queda prohibido a los Bancos de Emisión; I. Hacer operaciones de préstamo y descontar o negociar documentos de crédito, cuando el plazo del vencimiento pase de seis meses.

${ }^{46}$ AGN, Archivo: Acervo; Antiguos Bancos de Emisión, Fondo del Banco de Chiapas. Caja 2082, Libro S/N. Varios años.

${ }^{47}$ Ibíd.

${ }^{48}$ AHECH, Periódico Oficial, 27 de enero de 1906, p. 7.

49 AGN, Gobernación Periodo Revolucionario: Informe de Blas Corral, 1915, pp. 44-45.

50 Ibíd., pp. 44-45.

51 Ibíd., p. 90

${ }^{52}$ Esta moneda era la que circulaba en los países centro y sudamericanos y hacía las funciones de valor de cambio en las transacciones mercantiles en la región de Chiapas.

53 Desde 1917, con la aprobación de la Constitución Política de los Estados Unidos Mexicanos, la administración carrancista, que había analizado las deficiencias serias en que habían caído los bancos de Emisión en la época porfirista, además de la emisión indiscriminada de que habían hecho las facciones en pugna al emitir su propia moneda, decidió establecer el Banco de México, que tendría la misión de regular centralmente la emisión de moneda nacional.

54 AHECH, El Heraldo de Chiapas, enero 8 de 1907, Año 1, No. 27. El editorialista señalaba que: «En Comitán, Chilón, La Libertad y Tapachula, la moneda de poder liberatorio ilimitado es la peseta 'cachuca».

${ }^{55}$ AHECH, FFCG, Periódico quincenal, El Clavel Rojo, Comitán 29 de septiembre de 1901, Tomo 1, Núm. 7.

${ }^{56}$ AHECH, El Heraldo de Chiapas, Tuxtla Gutiérrez, diciembre 18 de 1906 Año 1, No. 24.

${ }^{57}$ Ibíd.

${ }^{58}$ AHECH, FFCG, Periódico quincenal, El Clavel Rojo, Comitán 29 de septiembre de 1901, Tomo 1, Núm. 7.

${ }^{59}$ AHECH, El Heraldo de Chiapas, Tuxtla Gutiérrez, diciembre 18 de 1906, Año 1, No. 24.

${ }^{60}$ AHECH, El Heraldo de Chiapas, Tuxtla Gutiérrez, diciembre 25 de 1906, Año 1, No. 25.

${ }^{61}$ AHECH, El Heraldo de Chiapas, Tuxtla Gutiérrez, diciembre 18 de 1906, Año 1, No. 24. ${ }^{62}$ Ibíd.

${ }^{63}$ AHECH, El Heraldo de Chiapas, Tuxtla Gutiérrez, enero 8 de 1907, Año 1, No. 27.

${ }^{64}$ Ibíd.

${ }^{65}$ Me refiero a los hechos sangrientos que se habían protagonizado en septiembre-octubre de 1911, entre

Tuxtla Gutiérrez y San Cristóbal, apoyado este segundo por la población Chamula.

${ }^{66}$ AHECH, La voz de Chiapas, Año 1, San Cristóbal Las Casas, Julio 09 de 1911, Núm. 25: «[...] que de acuerdo con los principios económicos, el pago de las contribuciones fiscales debe establecerse procurando el menor gravamen para el causante y la mayor comodidad para su pago, [sic] Por tales consideraciones, mientras se obtiene del Gobierno Federal la resolución conveniente para la substitución de la moneda extranjera por nacional en todo el Estado, el Gobierno Provisional, en ejercicio del pueblo y en beneficio de este, con apoyo del artículo 10 de la Ley de 24 de noviembre de 1910.- Acuerda: UNO.- Las Colecturías de Rentas y Tesorerías Municipales de los Departamentos de Las Casas, Comitán, La Libertad y Chilón, aceptarán en pago de los impuestos fiscales del Estado y Municipales, el peso fuerte centro y sud-americano a 90 cs., y las pesetas 20 cs., con exclusión de las otras especies fraccionarias de dicha moneda. [sic] El Gobernador Provisional, Manuel Pineda.- Srío. Gral. José H. Ruiz».

${ }^{67}$ AHECH, Memoria de Gobierno, Informe de Gobierno de Rafael Pimentel 1901.

${ }^{68}$ AHECH, El Heraldo de Chiapas, Tuxtla Gutiérrez, enero $1^{\circ}$ de 1907, Año 1, No. 26. 
${ }^{69}$ Ibíd.

${ }^{70} \mathrm{Ibíd}$.

${ }^{71}$ Ibíd.

${ }^{72}$ AHECH, El Heraldo de Chiapas, Tuxtla Gutiérrez, enero 15 de 1907, Año 1, No. 28.

${ }^{73}$ AHECH, HFCG, Diario de Chiapas, 31 de agosto de 1912.

${ }^{74}$ Foucault, Michel, Las palabras y las cosas. Una arqueología de las ciencias, dice: «...el hecho de que una moneda circule tanto más rápidamente cuando menos buena es, en tanto que las piezas con un alto índice de metal se encuentran escondidas y no figuran en el comercio: es la ley llamada de Gresham». Ed. Siglo XXI, Argentina, 1968, p. 168.

${ }^{75}$ Manero, Antonio, 'La revolución bancaria en México.', Ed. Somex y Miguel Ángel Porrúa. México, 1957. P. 125.

Fecha de recepción: 13 de julio de 2011.

Fecha de aceptación: 25 de enero de 2012. 